\title{
The Effect of Lexical-Temporal-Indicator Prompt vs. Metalinguistic Prompt on The Field-Dependent EFL Learners' Past Tense Acquisition
}

\author{
Nasrin Hadidi Tamjid \\ Department of English, Tabriz Branch, Islamic Azad University, Tabriz, Iran
}

Ehsan Narimani Vahedi (Corresponding Author)

Department of English, Tabriz Branch, Islamic Azad University, Tabriz, Iran

Email: narimani.ehsan@yahoo.com

\section{Doi:10.5901/mjss.2015.v6n3s2p482}

\section{Abstract}

This study investigated the efficacy of lexical-temporal-indicator (LTI) prompt vs. metalinguistic prompt among field-dependent (FD) learners in their acquisition of past tense. To this end, four intact classes at Iran Language Institute (ILI) with a total number of 86 teenage learners at elementary level were selected. A Group Embedded Figures Test was utilized to specify field-dependent learners. A pretest with a focus on past tense was used to ascertain that the learners were not familiar with the targeted feature. Two groups out of four classes with an equal number of $F D$ learners $(n=17, n=17)$ received $L T I$ and metalinguistic prompts as their treatments respectively. The one-month treatment was administered for the first 20 minutes of eight sessions. Then, an immediate parallel post-test was administered to compare the performance of the two groups. The findings revealed that FD learners receiving LTI prompt did better than those receiving metalinguistic prompt. Based on the findings, it can be concluded that LTI prompt is more favored than metalinguistic prompt by FD learners.

Keywords: lexical-temporal-indicator prompt; metalinguistic prompt; field-dependent learners;

\section{Introduction}

Language teaching as a multidisciplinary practical field is one of the fruitful areas of research in which intuition and theory play important roles. By the emergence of post-method era, the method and methodology trade-off in the classroom is undeniable. Method is defined as the theoretically grounded concept confirmed by the experts, while methodology incorporates what an individual teacher intuits uniquely in practice to meet the learners' needs and classroom objectives (Kumaravadivelu, 2006). Attributing the term methodology to reject one-size-fits-all approach entails the inclusion of individual differences according to different factors one of which is the learning style.

Learning style covers a set of almost fixed or acquired characteristics which the learner possesses to accost the problems through the emotionally or cognitively differentiated style. Learning styles tend not to change. And it varies interpersonally between individuals rather than intrapersonal like learning strategies. According to different factors, many learning styles have been posed like 'sensory preferences, analytic/gestalt, reflectivity/impulsivity, tolerance of ambiguity, and field independence/dependence'. A field dependent learner prefers to consider everything as a whole and contextualized without analyzing the formal details of language, while field independent learner inclines toward the logic of consciously analyzing the forms of language and can specify some parts out of whole easily (Ziahosseiny, 2009).

According to Vanpatten's (2004) input processing, every individual processes the received inputs in terms of his/her own meaning default rather than its grammatical features. It indicates that inputs are processed based on content which resides in the lexis. "Lexical preference principle" contributes the learners to make use of lexical clues in the input. In order to meet the individual difference which is the field dependency style in this study, "lexical-temporal-indicator prompt" as a contextual lexical clue, indicating the time, was utilized to serve the learners' self-correction in learning past tense. And, "metalinguistic prompt" which explicitly reminds the past tense rule was used to urge the learners to self correct. In other words, this study was an attempt to determine the possible conformity of metalinguistic prompt versus lexical-temporal-indicator (LTI) prompt to field dependent learners in past tense learning. 


\section{Review of the Related Literature}

This part paves the grounds for the specification of the areas in the literature which were fertile and required further elaboration to adapt and modify novel corrective feedback types. To this end, many studies (Lyster \& Ranta, 1997; Sheen, 2004; Corder, 1967; Pienemann, 1989; Chaudron, 1988; Efaf Soltani \& Azari, 2013; Soltanabadi Farshi \& Khalili Safa, 2015; Basturkmen \& Varnosfadrani, 2009; Aman, Mustaffa, Noor, \& Seong, 2010; Bitchener \& Knoch, 2008; Ahangari \& Amirzadeh, 2011) have been given a close look.

\subsection{Corrective Feedback Types}

Lyster and Ranta (1997) categorized corrective feedback into six different types according to learner uptake, as follows:

1. Explicit correction: The teacher clearly states what is wrong with the learners' utterance and provides the correct form.

2. Recast: The teacher keeps the message constant while correcting the utterance implicitly.

3. Clarification Request: The teacher uses some phrases like "Excuse me?" or "I don't understand" to indicate the learners that their utterances were erroneous or not understood.

4. Metalinguistic Feedback: The teacher provides technical information related to the learners' errors without explicitly correcting them.

5. Elicitation: The teacher requires the learners to elicit the correct form through asking questions, asking for reformulation, or completion of the teacher's utterance.

6. Repetition: The teacher repeats the learners' erroneous utterance intact to make them notice the ill-formed part.

In addition, Sheen (2004) defined multiple feedback types as the supplementary type which may include different types in a combined form. In light of Sheen's multiple feedback, and Lyster and Ranta's taxonomy, two innovative prompt types of Lexical Temporal Indicator and Metalinguistic were operationalized in this study.

\subsection{Differential effects of corrective feedback types}

Pros and cons of different studies, backed by different theories, triggered the inclusion of this part to justify the carrying out of this study.

Since every individual follows a relatively fixed developmental order of acquisition, the instruction should consider the learners' "built-in syllabus" (Corder, 1967). Accordingly, Pienemann (1989) proposed "learnability-teachability" hypothesis to draw the attention toward teaching language according to developmental order. However, some frequent language features necessitates their coverage in the syllabus like past tense which is among the lately acquired grammatical features. Teacher as the interventionist can provide learners with appropriate types of corrective feedback to precipitate the developmental order of acquisition. Corrective feedback is a kind of response provided with the learners' errors to make them revise their errors (Chaudron, 1988). According to Lyster and Ranta (1997), corrective feedback is categorized into six types, two of which are prompt and metalinguistic. Prompt is used as an elicitation technique for selfcorrection while metalinguistic feedback simply explains the rules.

In an outstanding study, Efaf Soltani and Azari (2013) proposed two sorts of feedback in the form-focused instruction that can help L2 learners to augment their semantic assets. This article explores the part of reactive form focused instruction including corrective feedback and different endeavors to attract learners' attention to the target feature amid communication and working on correcting writing errors. In this study 60 participants who had enlisted in "progressive composition" course at Azad university of Rasht, chose and passed OPT, 20 of subjects dispersed into two groups. After the pre-test, the errors in their written data were dissected by two different raters as far as distinguishing and ordering of the grammatical errors which were found in tenses, articles,.... This order was utilized as rules for arrangement as a part of experimental group. In the experimental group, from the recorded class exercises, Reactive Form-Focused Episodes/RFFES separated with a specific end goal to grantee whether the transaction happened around the pre-test linguistic use errors/grouping. Correlation between the method for pre- and post-test demonstrated that reactive form-focused oral feedback/negotiation had a greater impact on correcting grammatical errors than red-penunderlined correction in progressive composing class of Azad university of Rasht.

Soltanabadi Farshi and Khalili Safa (2015) investigated the impacts of two sorts of corrective feedback on EFL learners' writing skill. Thirty five advanced learners in three groups took part in this study. Structures of written texts were taught taking all things together three classes for fourteen sessions of treatment; and every session, a related point was 
given and the learners were gotten some information about it. In class A, the learners needed to convey their assignments to the teacher in classroom; then the teacher composed the corrective notes on their papers and gave their papers back the following session. In class B, participants needed to compose their assignments on their electronic instrument, and after that send written tasks by means of email to the teacher, and he likewise sent the corrective comments on their errors through email. In class C, as the control group, no corrective feedback was given to learners' errors in their written tasks. Also, in class C, learners were allowed to convey their compositions whether in class or via email. The results demonstrated both strategies to be powerful since the scores of both experimental results were significantly higher than the scores of the control group; however, electronic feedback was more powerful and productive than traditional sort; in light of the fact that scores of the learners in group B (electronic feedback) were significantly higher than class C (traditional feedback) (Soltanabadi Farshi \& Khalili Safa, 2015).

Basturkmen and Varnosfadrani (2009) carried out a research to explore the effects of different manners of correction (explicit vs. implicit correction) on learning of grammatical features. The study mainly focused on the effectiveness of explicit and implicit correction of developmental early vs. developmental late features. To tackle the posed questions, fifty-six intermediate level Iranian EFL learners were asked to read two passages and then retell the information in their own way. Based on the grammatical errors made, individual tests were developed. The learners received three types of treatment (correction): 1. Immediate explicit correction, 2. Delayed explicit correction, and 3. Immediate implicit correction. A pretest and a posttest were administered to observe the effectiveness of each treatment. The results revealed higher scores for explicitly corrected learners than implicitly corrected ones. These findings supported the argument regarding the role of metalinguistic awareness in language learning. Moreover, the analysis of the scores indicated that developmental early and late features are learned better with explicit and implicit correction respectively.

Aman, Mustaffa, Noor, and Seong (2010) investigated the effect of various verbal feedbacks that a group of primary school teachers put to use. This study sought to investigate the types of verbal feedbacks utilized by ESL teachers and identified the most frequently employed one. For this purpose, four experienced school teachers were given a close look by researchers in their classes. Real classrooms were audiotaped and transcribed for a whole lesson plan. Careful analysis of the data mainly obtained from transcriptions, showed that evaluative type feedback turned out to be the most frequent among others including: Repetition, Interactive feedback, and Corrective feedback. It was implied that mere existence of evaluative feedback forms such as "praises", do not lend support for learning. Therefore, different forms of evaluative feedbacks should be proportioned to the performance of the students and provide the teachers with influential teaching strategies. Also it was found that The I-R-F interaction pattern can regularly be found in most ESL classrooms. However, in this study, instances of prolonged sequences of teacher-initiated patterns, at times, made the lesson less communicative.

Bitchener and Knoch (2008) carried out a research to measure the effect of different types of written corrective feedbacks on ESL learners' performance. To achieve the mentioned goals, thirty-nine low intermediate ESL learners were treated through three different direct written corrective feedbacks (direct corrective feedback, written and oral metalinguistic explanation; direct corrective feedback and written meta-linguistic explanation; direct corrective feedback only) for a period of six month in New Zealand. The researchers tried to find out if there is a differential effect on accuracy when utilizing these three different direct corrective feedback options in a six month period. A pre-test post-test design was used to measure the accuracy in two functional uses of the English article system (referential indefinite "a" and referential definite "the") by low intermediate ESL learners. To investigate the long term effect of the treatments, a pretest on the first day, an immediate post-test, and then two delayed post-tests within an appropriate time interval (all within six months) were administered. The analysis of the results revealed that there was no statistically significant difference between the three post tests, that is, the only provision of error correction was just as effective as the additional provision of written and oral meta-linguistic explanation in low intermediate learners' acquisition of English article system. It was concluded that teachers should feel confident to make use of any different types of direct written corrective feedbacks on their students' linguistic errors.

Ahangari and Amirzadeh (2011) carried out a research to examine the relationship between learners' proficiency levels and teachers' choice of spoken corrective feedback in different levels. For this purpose, 20 elementary, 20 intermediate, and 20 advanced students (classified based on TOEFL proficiency test) with their EFL teachers were selected as the participants of this study. An MP3 player was used by the teachers to record their classes. Six classes at three levels were recorded for five straight sessions for an analysis of the interactions which took place in class. The researchers examined the recordings and transcribed those parts related to oral corrective feedbacks teachers provided in teacher-pupil interactions. Sixty moves from each class (totally 360 moves) formed a data base which was statistically analyzed to recognize the frequency of the corrective feedback types at each level. The results showed that recast was 
the most frequently used type of corrective feedback and translation was the least frequently used one at both elementary and intermediate levels. Moreover, at advanced levels, recast was the most frequently used while multiple feedback and translation types of corrective feedback were the least ones. In addition, it was concluded that as the learners' proficiency level increases, recast is used less frequently and consequently more types of corrective feedback are incorporated.

Several previous studies have yielded controversial positive and negative effects in terms of corrective feedback types. The studies considered different factors such as proficiency level, praises, explicit-implicit or providing new corrective feedback types in reaction to drawbacks of corrective feedback types especially on recast noticing problem. However, lack of any individualized corrective feedback study based on learning styles and developmentally late acquired features triggered this study.

\subsection{Operationalized Corrective Feedback Types}

a) Lexical Temporal Indicator Prompt: Since this study focused on the specific target structure of past tense, it was designed as a contextualized lexical clue that shows the past tense in reaction to the erroneous past tense use to implicitly urge learners self-correct. For example stating: yesterday? , last week? , etc.

b) Metalinguistic Prompt: It explicitly reminds the past tense rule to make learners self-correct. For example: past tense?

\subsection{Research questions}

1. Do lexical temporal indicator prompts have any significant effect on field dependent learners' past tense learening?

2. Do metalinguistic prompts have any significant effect on field dependent learners' past tense learning?

3. Is there any significant difference between two field dependent groups' performance in past tense acquisition receiving lexical temporal indicator prompts and metalinguistic prompts respectively, in learning past tense?

\section{Method}

This study was an attempt to investigate the effect of lexical temporal indicator prompt (LTI) versus metalinguistic prompt as the independent variables on past tense learning as the dependent variable. This research was a quasi-experimental quantitative study with a pretest-posttest design.

\subsection{Participants}

This study was conducted in the young-adult department of the Iran Language Institute (ILI), Urmia branch. Four elementary intact classes of Race 2 level with a total number of 86 learners within the age range of 11 to 14 were selected as the participants of this study. For the sake of homogeneity, the learners' previous term scores and placement test scores were considered and accordingly six were considered as the outliers. Screening pre-test results revealed that 18 learners were already familiar with the targeted feature and consequently their scores were not taken into account in the study. Corresponding to the ILI scoring criterion on the acceptable cut-off score of 60 out of 100, this study considered those who scored below the cut-off score of 30 out of 50 as the participants. Therefore, after specifying the field dependent learners by a questionnaire, 34 out of 86 learners were regarded as the main participants of this study and 28 field independent learners were excluded from the study. Finally, two groups with an equal number of FD learners $(\mathrm{N}=17, \mathrm{~N}=17)$ were selected. Moreover, group random assignment was used in the treatment procedure.

\subsection{Instrument}

The homogeneity of the participants was met by their previous term scores and placement test scores. In order to specify the field dependency or independency of the learners, Group Embedded Figure Test (Oltman, Raskin, \& Wilkin, 1971) was adopted. A thirty multiple-choice-question pretest and a parallel posttest were adapted from the ILI Test Time 3 book (Ghojogh, \& Hosseinzadeh, 2009) with a focus on the past tense. Each test included five distracter items, unrelated to the targeted feature, to control the subject expectancy. The pretest and posttest on the learners were piloted with similar characteristics, while some distractor items were not taken into account in the analysis section. Based on Cronbach's Alpha, the tests enjoyed acceptable reliability indices of 0.75 and 0.72 , respectively. In addition, the content validity of the 
tests was consulted with experienced colleagues at the ILI.

\title{
3.3 Procedure
}

This study aimed at determining the possible effects of different prompt types on the acquisition of the past tense among field dependant learners. Accordingly, four intact classes of Race 2 level at the ILI were selected as the participants of this study. The total number of 86 were reduced to 80 after excluding the outliers based on the homogeneity process of relying on previous term and placement test scores. As a result of the administration of the screening pretest, 18 learners, already familiar with the past tense, were not taken into account in the results of the study. Through the aforementioned procedure, 34 out of 86 learners were selected as the major participants of this investigation. A Figure Embedded Test (Oltman, Raskin, \& Wilkin, 1971) was used to determine the field dependent and field independent learners. According to the interpretation given by the questionnaire, those scored below 20 were specified as field dependent and above 30 as field independent. Based on the results, two groups with the highest number of FD learners ( $N=17, N=17$ ) were randomly treated through LTI prompt and metalinguistic prompt. In order not to allow the teachers' presentation of the past tense to intervene with the treatment as an extraneous factor, the pretest was administered after the presentation session so that different types of treatments were the only factors affecting learners' performance in the posttest. The treatment was administered for the first 20 minutes of eight consecutive sessions in a one-month period. In the group receiving LTI prompt treatment, the learners were asked to self correct by providing them with lexical temporal clues, adverbs of time, such as: yesterday, last week, last month, two days ago, etc. However, in those groups receiving metalinguistic prompt treatment, the learners' attention was drawn to the erroneous utterances by offering the past tense rule hint,

\author{
LTI group \\ Teacher: what did you do yesterday? \\ Student: I wash my our car yesterday. \\ Teacher: yesterday ... \\ Student: I washed our car yesterday. \\ Metalinguistic group \\ Teacher: what did you do last night? \\ Student: I watch TV last night. \\ Teacher: past tense ... \\ Student: I watched TV last night
}

Then, an immediate parallel posttest was given to compare the performance of the two groups. Since this study investigated the effect of two independent variables on one dependent variable, paired t-test and covariance analysis were run to analyze the data.

\section{Results}

This study was concerned with investigating whether the past tense acquisition of field dependent learners at the beginning of the study showed any difference at the end of the study. For this purpose, the pre-test and the post-test mean scores of LTI and Metalinguistic prompts groups were compared separately. The findings relating to these comparisons are shown in Table 1. According to the findings, there was a significant difference between the pre-test and post-test mean scores of both LTI prompts and Meta linguistic prompts groups. There was an improvement both in LTI prompts group ( $\mathrm{t}=-11.04, \mathrm{P}<0.001)$ and Meta linguistic prompts group $(\mathrm{t}=-5.91, \mathrm{P}<0.001)$ after the treatment. This statistically significant result suggests that giving a treatment in both LTI and Meta linguistic prompts provides field dependent learners an opportunity for developing their past tense learning skills.

Table 1. The comparison of pre-test and post-test past tense acquisition scores of research groups

\begin{tabular}{|c|c|c|c|c|c|c|c|c|c|}
\hline \multirow[t]{2}{*}{ Groups } & \multirow[t]{2}{*}{$n$} & Pre-test & \multicolumn{3}{|c|}{ Post-test } & \multirow[t]{2}{*}{ Mean difference } & \multirow[t]{2}{*}{ d.f. } & \multirow[t]{2}{*}{$T$} & \multirow[t]{2}{*}{$p$} \\
\hline & & Mean score & S.D. & Mean score & S.D. & & & & \\
\hline LTI prompts & 17 & 19.64 & 4.54 & 33.41 & 6.55 & -13.76 & 16 & -11.04 & 0.001 \\
\hline ML prompts & 17 & 18.47 & 4.03 & 24.59 & 6.03 & -6.12 & 16 & -5.91 & 0.001 \\
\hline
\end{tabular}


The second research question of the study investigated whether there was any difference between LTI prompts and Metalinguistic prompts in field dependent learners' acquisition of past tense. For this purpose, the post-test mean scores of $L T I$ and ML group on past tense acquisition were compared using one way analysis of covariance. In this study, independent variable was group membership (LTI or ML), dependent variable was learners' score on past tense word acquisition, and control variable was learners' pre-test scores. Before running ANCOVA, the homogeneity of regression slopes test was used to check interaction between the covariate and the experimental manipulation. The results of this test are illustrated in Table 2.

Table 2. Homogeneity of regression slopes

\begin{tabular}{ccccc}
\hline Sum of squares & Means squares & d.f. & $F$ & $p$ value \\
\hline 3.68 & 3.68 & 1 & 0.16 & 0.69 \\
\hline
\end{tabular}

As shown in Table 2, the $\mathrm{F}$ statistic was not significant $(\mathrm{p}<0.99)$. It may be concluded that there is no interaction between the covariate and the experimental manipulation. In Table 3, groups' descriptive statistics, and in Table 4 homogeneity of variance test hare given and the result of covariance analysis is reported in Table 5.

Table 3. Descriptive statistics of groups in post-test

\begin{tabular}{cccc}
\hline Group & $\mathrm{n}$ & Mean & SD \\
\hline LTI prompts & 17 & 33.41 & 6.54 \\
ML prompts & 17 & 24.59 & 6.03 \\
total & 34 & 29 & 7.65 \\
\hline
\end{tabular}

Table 4. Levene's test of homogeneity of variance

\begin{tabular}{cccc}
\hline$F$ & d.f.1 & d.f.2 & $p$ value \\
\hline 0.001 & 1 & 32 & 0.97 \\
\hline
\end{tabular}

According to the Table 4, the Levene's test was not significant $(p<0.97)$. Thus, it can be concluded that the variance of post-test scores is equal across groups.

Table 5. Covariance analysis to compare groups in post-test

\begin{tabular}{ccccccc}
\hline Source & SS & MS & $F$ & p value & d.f. & Effect size \\
\hline Pre test & 553.98 & 553.98 & 24.04 & 0.001 & 1 & 0.44 \\
Group & 492.02 & 492.02 & 21.35 & 0.001 & 1 & 0.41 \\
\hline
\end{tabular}

As shown in table $5, \mathrm{~F}$ statistic of group membership is significant at 0.001 alpha levels, after controlling the pre-test scores $(F=21.35, p<0.001)$. This finding shows that there are significant differences among groups in the post-test scores. Effect size statistic shows that group membership can predict 41 percent of variance in post-test scores. According to Table 3, LTI prompts group mean score (33.41) is higher than that of ML prompts group (24.59). The means difference (7.68) is significant at (0.001) alpha level. According to this finding, it may be concluded that the effect of LTI prompts on field dependent learners' past tense acquisition is higher than ML prompts.

\section{Discussion}

The results obtained from statistical analysis indicated that there was a significant difference between two FD groups' performance in the immediate post test receiving LTI prompt and metalinguistic prompt. In other words, FD learners showed inclination toward learning past tense through LTI prompt rather than through metalinguistic prompt. Corresponding to the findings of this study, and keeping in mind that past tense is a developmental late feature in language learning, Basturkmen, and Varnosfadrani (2009) found that developmental early features are learnt better through explicit corrective feedback, while developmental late features are learnt better through implicit corrective feedback. Parallel to individualized aspect of this study, Aman et al (2010) noticed that evaluative type feedback like 
"praises" was the most frequently one utilized by ESL teachers and claimed that it is not sufficient to the learning process and should be combined with other teaching strategies. It seems that teachers should be careful with their teaching strategies, especially with the ways to correct their learners since every individual holds different learning styles and strategies.

Contrary to our findings, Bitchener and Knoch (2008) maintained that employing different types of written corrective feedback on the learners' linguistic errors would have equal effect on the learning process. However, Herschell, Greco, Filcheck and McNeil (2002) argued that the nature of feedback should be to the point and specific rather than unplanned and general. Furthermore, related to providing different prompt types to challenge learners to correct themselves, Hatie and Timperly (2007) contended that learners' scaffolding interaction as feedback type (implicitly) leads learners to a beneficial hypothesis construction process while presenting all the solutions (explicitly) at the learners' disposal without challenging their linguistic system would be detrimental. In addition, Mackey, Gass, and McDonough (2000) claimed that greater participatory involvement demanded on the learners during interaction increases their noticing of erroneous forms. In contrast, they suggest that recasts may go unnoticed because they do not necessitate learners' participation. Thus, relying on the pros and cons of the related studies discussing the extent of learner-specific and generalizability of any type of corrective feedback to individual learners according to different factors like proficiency level surveyed in Ahangari and Amirzadeh (2011), this study proposed corrective feedback type specified according to learning style and learners' developmental order.

\section{Conclusion}

Error correction period moved from the time error was avoided to the time when errors were the signs of learning that can be ignored; corrective feedback (CF) necessitating corrective intervention emerged. However, corrective feedback takes a form of response to encourage learners' communication, and leads to self-correction. Considering that correction remaining unnoticed in the case of recast, innovative types of prompts including some target structure features were intuited to raise the learners' awareness and trigger their grammaring process (Larsen-Freeman, 2000). Therefore, this study employed two prompt types of Lexical Temporal Indicator prompt and Metalinguistic prompt to satisfy selfcorrection aspects of CF and considered field dependency learning style and past tense to conclude that correction can be varied according to individual differences and target structure, respectively. Based on the findings, the effectiveness of LTI prompt and metalinguistic prompt on the past tense acquisition was supported. In addition, comparing two field dependent groups receiving LTI prompt and metalinguistic prompt indicated that field dependent learners mostly conform to LTI prompt. Further studies concerning other learning styles and their preference of specific corrective feedback types would be a fruitful area of research. Also, taking into consideration some other factors like attitudes toward correction, motivation, and gender may yield to pedagogically useful results for further improvement of educational development.

\section{References}

Ahangari, S. and Amirzadeh, S. (2011). Exploring the teachers' use of spoken corrective feedback in teaching Iranian EFL learners at different levels of proficiency. Procedia - Social and Behavioral Sciences, 29, 1859-1868.

Aman, I., Mustaffa, R., Noor, N. M., and Seong, T. K. (2010). Teacher's verbal feedback on students response: A Malaysian ESL classroom discourse analysis. Procedia Social and Behavioral Sciences, 7(c) 398-405.

Basturkmen, H. and Varnosfadrani, A. D. (2009). The effectiveness of implicit and explicit error correction on learners' performance. System, 37, 82-98. Procedia - Social and Behavioral Sciences, 29, 1859-1868.

Bitchener, J. and Knoch, U. (2009). The relative effectiveness of different types of direct written corrective feedback. System, 37, 322329.

Chaudron, C. (1988). Second Language classrooms: Research on Teaching and Learning. Cambridge: Cambridge University Press.

Corder, S. P. (1967). The significance of learners' errors. International Review of Applied Linguistics, 5,161-169.

Efaf Soltani, F., and Azari, H. (2013). The role of reactive form -focused oral feedback in the devalopment of Iranian EFL Learners' grammatical accuracy in writing skill. Mediterranean Journal of Social Sciences, 4(4), 157-162.

Ghojogh, A. N., and Hosseinzadeh, S. (2009). Test Time 3. Iran Language Institute: Kanoonchap.

Hattie, J. and Timperley, H. (2007). The Power of Feedback. Review of Educational Research, 77, 81-112.

Herschell, A. D., Greco, L. A., Filches, H. A. and McNeil, C. B. (2002). Who is testing who? Intervention in School and Clinic, 37 (3), $140-$ 148.

Kumaravadivelu, B. (2006). Understanding language teaching: from method to postmethod. Mahwah, NJ: Lawrence Erlbaum.

Larsen-Freeman, D. (2000). Grammar: Rules and reasons working together. ESL Magazine, 3,10-12.

Lyaster, R., and Ranta, L. (1997). Corrective feedback and learner uptake: negotiation of for in communicative classrooms. Studies in Second Language Acquisition, 19(1), 37-66. 
Pienemann, M. (1989). Is language teachable? Psycholinguistic experiments and hypotheses. Applied Linguistics, 10, 52-79.

Sheen, Y. H. (2004). Corrective feedback and learner uptake in communicative classrooms across instructional settings. Language Teaching Research, 8(3), 263-300.

Soltanabadi Farshi, S., and Khalili Safa, S. (2015). The effect of two types of corrective feedback on EFL learners' writing skill. Advances in language and literary studies, 6(1), 26-30.

VanPatten, B. (2004). Input and output in establishing form-meaning connections. In B. VanPatten et al. (eds) Form-meaning Connections in Second Language Acquisition. (pp. 29-48). Mahwah, NJ: Lawrence Erlbaum.

Ziahosseiny, S. M. (2009). Teaching English as an L2: focusing on integrated skills. Tehran: Rahnama Press. 